\title{
Erratum to: Suppression of red rot caused by Colletotrichum falcatum on sugarcane plants using plant growth-promoting rhizobacteria
}

\author{
Muhammad Nadeem Hassan · Shahid Afghan • \\ Fauzia Yusuf Hafeez
}

Published online: 23 July 2010

(C) International Organization for Biological Control (IOBC) 2010

\section{Erratum to: BioControl (2010) 55:531-542 \\ DOI 10.1007/s10526-010-9268-z}

There were errors in the accession numbers for some strain codes specified in the original publication (in Table 1 and in the text on pages 7 and 8). The following list gives the correct numbers:
NH-5 EF449772

NH-50 EU627168

NH-100 EU627167

NH-160 EU627169

NH-217 EU627170

NH-300 EU627172

The online version of the original article can be found under doi:10.1007/s10526-010-9268-z.

M. N. Hassan · F. Y. Hafeez ( $\square)$

National Institute for Biotechnology and Genetic Engineering (NIBGE), P. O. Box 577, Jhang Road, Faisalabad, Pakistan e-mail: fauzia@comsats.edu.pk; fauzia_y@yahoo.com

M. N. Hassan

e-mail: nadeem_hassan@comsats.edu.pk;

hassan.scholar@gmail.com

Present Address:

M. N. Hassan · F. Y. Hafeez

Department of Biosciences, COMSATS Institute

of Information Technology, Chak Shahzad Campus,

Park Road, Islamabad, Pakistan

\section{S. Afghan}

Shakarganj Sugar Research Institute (SSRI),

Jhang, Pakistan

e-mail: shahid.afghan@shakarganj.com.pk 